\title{
A Brief Review of the Risks and the Stratification of Sudden Death in the Ventricular Pre-Excitation Syndrome
}

Clóvis Fröemming Junior ${ }^{1, *}$, Tiago Luiz Luz Leiria1, Gustavo Glotz de Lima1, Leonardo Martins Pires ${ }^{1}$, Marcelo Lapa Kruse1, Thiago Camargo Moreira1', Javier Fernando Vasquez Pinos ${ }^{1}$, Bruno Schaaf Finkler ${ }^{1}$, Danilo Barros Zanotta ${ }^{1}$

\section{ORCID IDs}

Fröemming Junior C (D) https://orcid.org/0000-0002-4770-0050

Leiria TLL (D) https://orcid.org/0000-0002-3095-102X

Moreira TC (D) https://orcid.org/0000-0001-6907-2895

Lima GG (D) https://orcid.org/0000-0003-0097-5206

Pires LM (D) https://orcid.org/0000-0001-8003-8081

Pinos JFV (D) https://orcid.org/0000-0001-7237-6136

Finkler BS (D) https://orcid.org/0000-0001-6885-3710

Kruse ML (D) https://orcid.org/0000-0002-2429-4491

Zanotta DB (D) https://orcid.org/0000-0001-5372-0421

\begin{abstract}
Objective: The diagnosis of ventricular preexcitation syndromes is often occasional and with underestimated risk, showing controversies in its stratification and indication of prophylactic ablation. This work aims to explore and summarize the data in the literature, exposing the authors' conclusions regarding this review. Methods: The authors prepared this work based on the latest guideline of the European Society of Cardiology plus a search for articles published in MEDLINE whose titles related to sudden death from ventricular fibrillation in patients with ventricular preexcitation. Discussion: Sudden death secondary to preexcited atrial fibrillation with degeneration to ventricular fibrillation is the most feared event in Wolff-Parkinson-White syndrome, has an average annual incidence of 0.15 to $0.39 \%$, affecting individuals with structurally normal heart. The noninvasive stratification methods do not demonstrate adequate efficacy, and an electrophysiological study is recommended for all cases at the time of diagnosis. The most severe criteria for sudden death are shortest preexcited RR interval $\leq 250$ ms (SPERRI or SPRRI); accessory pathway effective refractory period (APERP) $\leq 250 \mathrm{~ms}$; presence of multiple accessory bundles; shortest paced cycle length with preexcitation during atrial pacing $\leq 250 \mathrm{~ms}$ (SPPCL); Ebstein anomaly; induction of sustained supraventricular tachycardia. Conclusion: The low rate of complications during the diagnostic exam as well as in the therapeutic procedure, added to the high percentage of success of radiofrequency ablation, leads to indicate early the execution of electrophysiological study as a more diligent and accurate measure in the reduction of sudden death events in patients with ventricular preexcitation syndromes.
\end{abstract}

KEYWORDS: Preexcitation; Accessory pathway; Wolff-Parkinson-White Syndrome.

1. Instituto de Cardiologia - Fundação Universitária de Cardiologia - Porto Alegre/RS - Brazil.

*Corresponding author: clovis.cardio@gmail.com

Received: May 26, 2020 | Accepted: Jul 25, 2020 


\section{INTRODUCTION}

With an annual incidence of between 0.15 and $0.39 \%$, sudden death as the first clinical manifestation of WolffParkinson-White Syndrome (WPWS) is a rare but well-documented event ${ }^{1,2}$.

The event occurs in patients with acute atrial fibrillation with high ventricular response and anterograde conduction through an accessory bundle. Rapid ventricular stimulation leads to a deterioration of the rhythm and triggers ventricular fibrillation ${ }^{2,3}$.

The diagnosis of ventricular pre-excitation syndromes is often occasional and of underestimated risks, presenting controversies in its stratification and therapeutic orientation, which may evolve with catastrophic outcomes ${ }^{2,3}$.

\section{METHODS}

The authors prepared this work based on the latest guideline of the European Society of Cardiology plus a search for articles published in MEDLINE, whose titles related to sudden death from ventricular fibrillation in patients with ventricular pre-excitation, highlighting the risk factors and stratification methods. The purpose of this review was to summarize a subject with controversial conceptions, exposing its conclusions based on the current literature and its experience.

\section{A brief historical review}

In 1930, Wolff et al. ${ }^{4}$ described a clinical syndrome in young patients without structural cardiological changes with a surface electrocardiogram showing an enlargement of the QRS complex (bundle branch block pattern) and an abnormal shortening of the P-R interval. This syndrome was accompanied by episodes of paroxysmal tachycardias and a paradoxical effect of vagal stimulation in the P-R interval.

Twenty-two years after the publication of this milestone in the history of cardiology, Holzmann and Scherf $f^{5}$ were the first to describe pre-excitation as a phenomenon of anterograde conduction through an accessory bundle, an embryological remnant of incomplete closure of the tricuspid and mitral rings. Soon after, Pick et al. ${ }^{6-8}$ revealed that the arrhythmias exhibited by patients with WPWS were attributed to differences in electrical properties between an accessory pathway and the atrioventricular node.

In 1967, Drs. Durrer e Wellens ${ }^{9,10}$ proved the possibility of inducing tachycardia with a narrow QRS in these patients. The application of an artificial extra-stimulus to the heart induced a tachycardia whose anterograde activation spread through the atrioventricular node and retrograde activation through the accessory bundle. This understanding of the mechanism of arrhythmia opened the door to a therapeutic approach. That same year, Burchell et al. ${ }^{11}$ used epicardial mapping to locate an accessory bundle on the right and perform an application of procaine to the myocardium, obtaining a temporary pre-excitation block.

In 1968, Cobb et al. ${ }^{12}$ and the Duke University team performed the first surgical ablation of an accessory bundle. After this step, Duke University became the epicenter of the knowledge of this arrhythmia, raising concerns from the beginning about the lethality of the ventricular pre-excitation syndrome in young, asymptomatic individuals with a structurally healthy heart.

In 1979, Klein et al. ${ }^{13}$ compared electrophysiological findings in 25 patients, predominantly young adults, with WPWS and documented ventricular fibrillation versus 73 pre-excited patients, but without ventricular fibrillation. They found that finding a pre-excited R-R interval $\leq 250 \mathrm{~ms}$ during atrial fibrillation (SPERRI, SPRRI or shortest pre-excited RR interval) was the most relevant predictor for distinguishing patients at high risk for ventricular fibrillation.In that same work, short effective anterograde refractory periods of the accessory bundle (accessory pathway effective refractory period or APERP) showed overlap with the SPERRI data, however, in this initial phase, they were considered a very poor risk marker. 


\section{DISCUSSION}

Sudden death secondary to pre-excited atrial fibrillation with degeneration to ventricular fibrillation is the most feared event in patients with WPWS, has an average annual incidence of 0.15 to $0.39 \%$, has a predilection for young individuals (higher incidence of potentially fatal in individuals under 40) and may be the first clinical manifestation of the disease ${ }^{2,14}$.

Although the indication for electrophysiological study (EPS) and ablation for all patients with ventricular pre-excitation is quite reasonable, the difficult application on a large scale and possible complications as well as technical limitations due to the location of the anomalous bundle generate weight in the decision.

Only one in five asymptomatic patients will manifest arrhythmias related to the accessory pathway during their lifetime, with orthodromic reentry tachycardia being the most common form ${ }^{3}$.

The rationale brought from past guidelines pointed to a reasonableness in carrying out a first assessment with non-invasive stress methods. A 24-hour stress test or Holter that demonstrates the sudden disappearance of pre-excitation as well as the recording of an electrocardiogram without a delta wave predict the presence of a long anterograde refractory period and, therefore, low risk for malignant arrhythmic events. On the other hand, the persistence of conduction by the bundle during the simulation of physical activity with maximum heart rate, for example in an exercise test, predicts a SPERRI $<250 \mathrm{~ms}$ with a sensitivity of $96 \%$ (specificity of $17 \%$, positive predictive value $40 \%$ and negative predictive value of $88 \%$ ) $^{3,15,16}$.

Unfortunately, the results of the stress test are sometimes not binary - persistence or not - sometimes it is possible to identify intermittent pre-excitation during rest, but manifested throughout the period of exertion. You can see a progressive disappearance of the delta wave, indicating that an increase in sympathetic tone causes a preference for anterograde conduction by the atrioventricular node in front of an accessory bundle located in the more peripheral region, such as the left side.

Although intermittent pre-excitation is believed to be a predictor of anterograde poor conduction via the accessory pathway, it does not exclude the possibility of orthodromic tachycardia. Fitzsimmons et al. ${ }^{17}$ followed 196 military airmen with asymptomatic pre-excitation for an average period of 21 years and reported the development of tachycardia in $23 \%$ of those with constant pre-excitation compared to only $8 \%$ of those who showed it intermittently ${ }^{17-19}$. Therefore, despite a reduction in the probabilities, the manifestation of intermittent pre-excitation does not exclude the risks of arrhythmia.

The most recent guideline of the European Society of Cardiology (ESC) cited studies published in the last 30 years that stressed the importance of knowing the electrophysiological properties of the accessory bundle and that questioned the reliability of non-invasive methods for stratifying risk in asymptomatic patients. Its recommendations are to conduct an electrophysiological study in athletes or individuals with high-risk activity (professional or recreational) and for those who have not demonstrated low-risk criteria in a non-invasive test, which can be considered for all asymptomatic patients (Table 1$)^{3}$.

Table 1. Data according to the recommendations table of the last ESC management guideline for patients with supraventricular tachycardia.

\begin{tabular}{|c|c|c|}
\hline Recommendation & Level & Class \\
\hline $\begin{array}{l}\text { An EPS is recommended, with the use of isoprenaline, to stratify individuals with asymptomatic pre- } \\
\text { excitation who have high-risk occupations / hobbies, and those who participate in competitive athletics. }\end{array}$ & । & B \\
\hline $\begin{array}{l}\text { Invasive risk stratification with an EPS is recommended in patients without "low risk" characteristics in } \\
\text { non-invasive risk stratification. }\end{array}$ & । & C \\
\hline $\begin{array}{l}\text { The performance of an EPS to stratify the risk of individuals with asymptomatic pre-excitation } \\
\text { should be considered. }\end{array}$ & $\| \mathrm{a}$ & B \\
\hline $\begin{array}{l}\text { The non-invasive assessment of the conductive properties of the accessory pathway in individuals with } \\
\text { asymptomatic pre-excitation can be considered. }\end{array}$ & $\mathrm{Ilb}$ & B \\
\hline
\end{tabular}

Although non-invasive tests are useful, the time required to perform them, their costs and the postponement of definitive interventionist conduct in high-risk cases can increase the rates of unfavorable outcomes. It is preferable and consensus among specialists, to employ a more direct strategy and refer for electrophysiological study as soon as the case of ventricular pre-excitation syndrome is identified. 
In the cardiac electrophysiological study, we seek to assess the properties of anterograde conduction of the accessory pathway to classify the risk of the disease and indicate the need for radiofrequency ablation. In this examination, mild sedation accompanied by local anesthesia in the femoral region can be used, as well as general anesthesia, and when opting for the latter, administer isoproterenol to decrease the effects of sedatives on the conductance properties of the accessory bundle ${ }^{20,21}$.

During the stimulation protocols, the data evaluated are: APERP, SPERRI, shortest paced cycle length with preexcitation during atrial pacing or SPPCL, confirmation of the presence of one or multiple accessory pathways, as well as, if it is possible to induce sustained supraventricular tachycardias $3,22,23$.

The identification of a SPERRI $\leq 250 \mathrm{~ms}$ seems to be, among all, the most significant marker for high risk ${ }^{19}$.In the absence of its measurement, the meeting of an SPPCL or APERP $\leq 250 \mathrm{~ms}$ has a very similar value ${ }^{22}$.

In general, in studies carried out by Kubuš et al. ${ }^{24}$ and Di Mambro et al. ${ }^{20}$, ablative therapy was proposed for all patients in high-risk groups. In addition to changes in SPERRI and APERP, these patients were also classified as having multiple accessory bundles $(\geq 2)$ and or when they presented induction of supraventricular tachycardia during the electrophysiological study ${ }^{20,24}$.

\section{CONCLUSION}

This work seeks to inform that the ventricular pre-excitation syndrome brings risks that must be faced with circumspection. Asymptomatic patients should always be referred for stratification, the electrophysiological study being the method of choice.

Mild measures such as non-invasive clinical stratification and underestimation of cases with intermittent pre-excitation, as mentioned in articles published over the past 30 years, can cause irreparable damage and should be discouraged.

According to the latest guideline for the management of patients with supraventricular arrhythmia, the main indicators of high risk for ventricular fibrillation are young patients ( $<39$ years), SPERRI $\leq 250 \mathrm{~ms}$, APERP $\leq 250 \mathrm{~ms}$, SPPCL $\leq 250 \mathrm{~ms}$, presence of multiple bundles (estimated incidence of 50\% in patients with Ebstein's anomaly), induction of sustained supraventricular tachycardia during EPS.

The low rate of complications both during the diagnostic exam and in the therapeutic procedure, even in pediatric populations, added to the high percentage of success of radiofrequency ablation, makes the early execution of an electrophysiological study indicated as a more diligent and accurate measure in reducing sudden death events in patients with ventricular pre-excitation syndromes.

\section{REFERENCES}

1. Munger TM, Packer DL, Hammill SC, Feldman BJ, Ballard DJ, Holmes Junior DR, et al. A population study of the natural history of WolffParkinson-White syndrome in Olmsted County, Minnesota, 1953-1989. Circulation. 1993;87(3):866-73. https://doi.org/10.1161/01. CIR.87.3.866

2. Blomström-Lundqvist C, Scheinman MM, Aliot EM, Alpert JS, Calkins H, Camm AJ, et al. ACC/AHA/ESC guidelines for the management of patients with supraventricular arrhythmias*_executive summary: a report of the American college of cardiology/American heart association task force on practice guidelines and the European society of cardiology committee for practice guidelines (writing committee to develop guidelines for the management of patients with supraventricular arrhythmias) Developed in Collaboration with NASPE-Heart Rhythm Society. J Am Coll Cardiol. 2003;42(8):1493-531.

3. Brugada J, Katritis DG, Arbelo E, Arribas F, Bax JJ, Blomström-Lundqvist C, et al. 2019 ESC Guidelines for the management of patients with supraventricular tachycardia The Task Force for the management of patients with supraventricular tachycardia of the European Society of Cardiology (ESC): Developed in collaboration with the Association for European Paediatric and Congenital Cardiology (AEPC). Eur Heart J. 2020;41(5)655-720. https://doi.org/10.1093/eurheartj/ehz467

4. Wolff L, Parkinson J, White PD. Bundle-branch block with short PR interval in healthy young people to paroxysmal tachycardia. Am Heart J. 1930;5(6):685-704. https://doi.org/10.1016/S0002-8703(30)90086-5 
5. Holzmann M, Scherf DT. Über elektrokardiogramme mit verkurzter Vorhof-Kammer Distanz und positiven P. Zacken. Z Klin Med. 1932;121:404-10.

6. Pick A, Katz LN. Disturbances of impulse formation and conduction in the pre-excitation (WPW) syndrome-Their bearing on its mechanism. Am J Med. 1955;19(5):759-72. https://doi.org/10.1016/S0002-9343(55)80021-6

7. Pick A, Langendorf R. Recent advances in the differential diagnosis of A-V junctional arrhythmias. Am Heart J. 1968;76(4):553-75. https://doi.org/10.1016/0002-8703(68)90143-9

8. Katz LN, Pick A. Clinical electrocardiography: Part I the arrhythmias: with an atlas of electrocardiograms. Philadelphia: Lea \& Febiger; 1956. pp. 679-708.

9. Durrer D, Schoo L, Schuilenburg RM, Wellens HJJ. The Role of Premature Beats in the Initiation and the Termination of Supraventricular Tachycardia in the Wolff-Parkinson-White Syndrome. Circulation. 1967;36(5):644-62. https://doi.org/10.1161/01.CIR.36.5.644

10. Wellens HJJ, Schuilenburg RM, Durrer D. Electrical Stimulation of the Heart in Patients with Wolff-Parkinson-White Syndrome, Type A. Circulation. 1971;43(1):99-114. https://doi.org/10.1161/01.CIR.43.1.99

11. Burchell HB, Frye RL, Anderson MW, McGoon DC. Atrioventricular and ventriculoatrial excitation in Wolff-Parkinson-White syndrome (Type B): Temporary ablation at surgery. Circulation. 1967;36(5):663-72. https://doi.org/10.1161/01.CIR.36.5.663

12. Cobb FR, Blumenschein SD, Sealy WC, Boineau JP, Wagner GS, Wallace AG. Successful Surgical Interruption of the Bundle of Kent in a Patient with Wolff-Parkinson-White Syndrome. Circulation. 1968;38(6):1018-29. https://doi.org/10.1161/01.CIR.38.6.1018

13. Klein GJ, Bashore TM, Sellers TD, Pritchett EL, Smith WM, Gallagher JJ. Ventricular fibrillation in the Wolff-Parkinson-White syndrome. N Engl J Med. 1979;301(20):1080-5. https://doi.org/10.1056/NEJM197911153012003

14. Pappone C, Vicedomini G, Manguso F, Saviano M, Baldi M, Pappone A, et al. Wolff-Parkinson-White Syndrome in the era of catheter ablation: insights from a registry study of 2169 patients. Circulation. 2014;130(10):811-9. https://doi.org/10.1161/ CIRCULATIONAHA.114.011154

15. Bershader RS, Cecchin Filho BC. Exercise testing for risk assessment in pediatric Wolff-Parkinson-White syndrome. Heart Rhythm. 2007;4(5):138-9.

16. Daubert C, Ollitrault J, Descaves C, Mabo P, Ritter P, Gouffault J. Failure of the exercise test to predict the anterograde refractory period of the accessory pathway in Wolff Parkinson White syndrome. Pacing Clin Electrophysiol. 1988;11(8):1130-8. https://doi. org/10.1111/j.1540-8159.1988.tb03964.x

17. Fitzsimmons PJ, McWhirter PD, Peterson DW, Kruyer WB. The natural history of Wolff-Parkinson-White syndrome in 228 military aviators: a long-term follow-up of 22 years. Am Heart J. 2001;142(2):530-6. https://doi.org/10.1067/mhj.2001.117779

18. Klein GJ, Gulamhusein SS. Intermittent preexcitation in the Wolff-Parkinson-White syndrome. Am J Cardiol. 1983;52(3):292-6. https:// doi.org/10.1016/0002-9149(83)90125-X

19. Cohen MI, Triedman JK, Cannon BC, Davis AM, Drago F, JanousekJ, et al. PACES/HRS Expert Consensus Statement on the Management of the Asymptomatic Young Patient with a Wolff-Parkinson-White (WPW, Ventricular Preexcitation) Electrocardiographic Pattern: Developed in partnership between the Pediatric and Congenital Electrophysiology Society (PACES) and the Heart Rhythm Society (HRS). Endorsed by the governing bodies of PACES, HRS, the American College of Cardiology Foundation (ACCF), the American Heart Association (AHA), the American Academy of Pediatrics (AAP), and the Canadian Heart Rhythm Society (CHRS). Heart Rhythm. 2012;9(6):1006-24. https://doi.org/10.1016/j.hrthm.2012.03.050

20. Di Mambro C, Drago F, Milioni M, Russo MS, Righi D, Placidi S, et al. Sports eligibility after risk assessment and treatment in children with asymptomatic ventricular pre-excitation. Sports Med. 2016;46(8):1183-90. https://doi.org/10.1007/s40279-016-0475-3

21. Yildirim I, Özer S, Karagöz T, Şahin M, Özkutlu S, Alehan D, Çeliker A. Clinical and electrophysiological evaluation of pediatric WolffParkinson-White patients. Anatol J Cardiol. 2015;15(6):485-90. https://doi.org/10.5152/akd.2014.5462

22. Etheridge SP, Escudero CA, Blaufox AD, Law IH, Dechert-Crooks BE, Stephenson EA, et al. Life-threatening event risk in children with Wolff-Parkinson-White syndrome: a multicenter international study. JACC: Clin Electrophysiol. 2018;4(4):433-44. https://doi. org/10.1016/j.jacep.2017.10.009

23. Timmermans C, Smeets JLRM, Rodriguez L-M, Vrouchos G, von den Dool A, Wellens HJJ. Aborted sudden death in the WolffParkinson-White syndrome. Am J Cardiol. 1995;76(7):492-4. https://doi.org/10.1016/S0002-9149(99)80136-2

24. Kubuš P, Vít P, Gebauer RA, Materna O, JanoušekJ. Electrophysiologic profile and results of invasive risk stratification in asymptomatic children and adolescents with the Wolff-Parkinson-White electrocardiographic pattern. Circ Arrhythm Electrophysiol. 2014;7(2):21823. https://doi.org/10.1161/CIRCEP.113.000930 